CHAPTER 4

\title{
Fertilizer Policies and Implications for African Agriculture
}


gricultural productivity growth has long been recognized as an important instrument to reduce poverty, generate nonfarm employment, and hence trigger structural transformation processes (see, for example, Timmer 1997; Fan, Hazell, Thorat 1999; Johnson 2000; and Mellor 2000). A central element in increasing agricultural productivity is the adoption of improved inputs, especially improved cultivars and inorganic fertilizer (Rosegrant and Evenson 1992; Ruttan 2002; Evenson and Gollin 2003). When combined with irrigation and improved management practices, these inputs can dramatically enhance yields and the overall returns to farming (see, for example, Evenson 2001).

While the productivity gains of improved input use and its economywide impacts on economic growth and poverty reduction were realized in many parts of Asia beginning in the 1960s, few African countries have enjoyed similar gains In particular, relatively fewer African farmers have substantially increased their use of improved cultivars or inorganic fertilizers (see, for example, Crawford et al. 2003; Henao and Baanate 2006; Morris et al. 2007; AGRA 2019). This should not imply that farmers are unaware of such inputs and their impacts: there is considerable evidence to indicate that farmers understand how to use improved cultivars and inorganic fertilizer (Sheahan and Barrett 2017), and there is considerable experience to suggest that widespread use can enhance productivity growth under the right conditions (Jayne et al. 2003; Rashid et al. 2013).

But overall, the use rates of these improved inputs remain low throughout much of Africa, particularly for inorganic fertilizer, which is the focus of this chapter. For instance, in 2017, the aggregate application of nutrients (that is, nitrogen, phosphate, and potassium) on the total cropland of the continent was estimated at 23 kilograms per hectare, which is about eightfold lower than the application rates in Asia during the same year (FAO 2020). Several factors explain the low use of fertilizer and other productivity-enhancing improved inputs in the region, including market imperfections, risk and uncertainty, credit constraints, farm size, low yield response, and behavioral factors (Marenya and Barrett 2009; Foster and Rosenzweig 2010; Duflo, Kremer, and Robinson 2011; Suri 2011).

In response to the low adoption of improved inputs, African governments have pursued various fertilizer promotion policies and programs. These initiatives range from state-controlled procurement and distribution systems to wholly private sector-led systems. This chapter reviews the pros and cons of some of these polices and their implications for fertilizer use and agricultural productivity.
We also review general trends in fertilizer consumption and application rates, marginal returns to fertilizer use, trends in tailored recommendations for nutrients based on soil tests, and emerging concerns regarding unbalanced use of fertilizer in fragile regions of the continent.

\section{A Global and Continental Angle on Fertilizer Polices in Africa}

The need to boost agricultural production and low fertilizer use rates has induced calls for African governments to take more concrete policy actions. For instance, under the Comprehensive Africa Agriculture Development Programme (CAADP), African governments committed to doubling agricultural productivity by focusing on the provision of improved inputs. African policymakers came together in 2006 at the Africa Fertilizer Summit in Abuja, Nigeria, and declared fertilizer a strategic commodity and resolved that African Union member states should promote the use of fertilizer via targeted subsidies (AUC 2006). The Abuja Declaration specifically called for member states to increase their fertilizer consumption to 50 kilograms per hectare by 2015 from 8 kilograms per hectare in 2006 (AUC 2006). The declaration also set forth 10 additional resolutions that identify interventions to be carried out at the regional and country levels to help achieve this target, for example, establishment of policy and regulatory frameworks, introducing targeted subsidies, and improving access to complementary inputs.

This declaration was followed by the Malabo Declaration on Accelerated Agricultural Growth and Transformation for Shared Prosperity and Improved Livelihoods, committed to by African heads of state at the marking of the 10th anniversary of CAADP. The Malabo Declaration affirmed the need to improve access to quality and affordable modern inputs through the provision of "smart" protection-subsidies that are carefully targeted and managed - to smallholder agriculture (AUC 2014).

While these declarations continue to be instrumental in providing overarching frameworks for fertilizer promotion on the continent, their impacts, as measured by the progress made thus far on the specific resolutions and commitments, remain mixed. For instance, the declarations inspired some countries to update or reformulate their fertilizer polices and regulations (for example, Burkina Faso, Ghana, Kenya, Mali, Mozambique, Rwanda, Tanzania, Uganda, and Zambia), but there are still many countries in Africa that do not have a 
coherent fertilizer policy and, instead, rely on decrees and ad hoc guidelines or statements. Likewise, substantial improvements in fertilizer use, both in total consumption and in application rates, have been made since the Abuja Declaration, but current levels are still remarkably low, lag far behind targets, and vary considerably across countries (AUC 2006; Sheahan and Barrett 2017; FAO 2020). Progress toward meeting the other Abuja resolutions is inadequate, except in the areas of fertilizer production and trade promotion, reducing the distance traveled to purchase fertilizer, and provision of subsidies for smallholder farmers (AGRA 2019).

Sandwiched between the Abuja and Malabo Declarations was what may have been the most important political driver of fertilizer policy in Africa today: the 2007-2008 food price crisis. The crisis reinvigorated the case for state involvement in fertilizer procurement, distribution, and pricing. When global prices for agricultural commodities-including food staples-skyrocketed during the crisis, many policymakers turned to fertilizer subsidies as a means of quickly increasing domestic food production (Jayne and Rashid 2013; Resnick and Mather 2016).

\section{Regional Initiatives on Fertilizer Policy and Markets in Africa}

CAADP, the Abuja and Malabo Declarations, and the food price crisis both inspired and built upon regional initiatives in Africa that were similarly designed to increase fertilizer use among farmers. Policy initiatives at inter- and intraregional levels have focused primarily on the implementation of two specific resolutions contained in the Abuja Declaration: (1) the harmonization of fertilizer polices and regulations and (2) the promotion of national/regional fertilizer production and intraregional trade. Some notable initiatives include the following (AGRA 2019).

In 2012, the Economic Community of West African States (ECOWAS) adopted protocols for the harmonization of fertilizer polices and regulations. ECOWAS, through its specialist agency, the Regional Agricultural Investment Plan for Food Security and Nutrition, adopted harmonized input subsidy policies across member states.

The East African Community (EAC) made similar advances in 2014, when it adopted a harmonized regulatory framework and procedures for fertilizer markets. The bloc also reviewed existing policies, standards, legislation, and regulations and finally developed guidelines on how harmonization of fertilizer policies and regulatory frameworks should be undertaken in the EAC.

In 2014, the Common Market for Eastern and Southern Africa (COMESA) and its agency, the Alliance for Commodity Trade in Eastern and Southern Africa, launched a Joint Program on Fertilizer Policy and Regulatory Harmonization in partnership with the African Fertilizer and Agribusiness Partnership. The program intends to harmonize fertilizer policies and fertilizer financing mechanisms. Relatedly, the Southern African Development Community (SADC) assessed fertilizer production opportunities in the region in 2010 in collaboration with the International Fertilizer Development Center and recommended regional harmonization of fertilizer standards.

There is also a tripartite initiative among regional economic communities and unions on harmonization of fertilizer polices and regulations and promotion of interregional fertilizer trade. However, the main shortfall with regard to regional initiatives is implementation. For instance, according to the Abuja Declaration scorecard, while good progress has been made on fertilizer production and trade, harmonization of polices and regulations is rated as unsatisfactory (AGRA 2019). Regional economic communities can play a crucial role in advancing the existing initiatives through inducing political commitment among member states.

\section{Fertilizer Promotion Polices in Practice: Mixed Evidence of Success}

In response to these global, continental, and regional initiatives, a number of African countries have further refined their policy approaches to fertilizer procurement, distribution, and pricing. Some have abandoned state-led fertilizer polices and adopted deep market reform policies, while others have returned to universal subsidies and state-led distribution (Druilhe and Barreiro-Hurlé 2012). A prominent example of the latter is the universal fertilizer subsidy programs in Malawi (Levy 2005; Minot and Benson 2009; Jayne et al. 2018). Although policy changes in some countries suggested that governments were learning from experience and adapting policy to emerging evidence, changes in many other countries were motivated primarily by political exigencies.

Despite this mixed record of progress, a clear typology of fertilizer policy regimes has emerged across Africa. Two broad categories of policies intended to 
incentivize fertilizer use are noteworthy. The first is state-led fertilizer marketing polices, which are closely associated with universal or near-universal subsidies on fertilizer price. These policies place the state at the center of fertilizer procurement, pricing, and distribution, and were common in many African countries from the 1960s to the early 1980s. While there is evidence of increased fertilizer use among farmers, especially in the later years of this period (Eicher 1995; Byerlee and Eicher 1997), the design and implementation of these policies came with high fiscal costs, market-distorting effects, and rent-seeking behavior (Jayne and Jones1997; Morris et al. 2007; Yamano and Arai 2010).

The second category of policies introduced more market-led fertilizer procurement and distribution mechanisms and followed from the structural adjustment programs that many African governments signed on to in the 1980s and 1990s. As these reforms varied across countries in terms of depth, breadth, sophistication, and level of implementation, results were unsurprisingly mixed and often controversial (Jayne et al. 2002, 2003; Minot and Benson 2009).

More important than the question of how to design and implement fertilizer policies in Africa is the emerging evidence on why such policies are insufficient to achieve agricultural productivity growth and its associated gains. Evidence has accumulated in the past decade to suggest that fertilizer subsidies alone are not sufficiently effective to increase the supply of food staples without complementary policies related to investment in roads, irrigation, and other rural infrastructure. In particular, investments in the development of agricultural commodity markets; improvement in extension services and the promotion of integrated soil fertility management practices; encouragement of private sector participation in commercial fertilizer markets; and other policies related to taxes, tariffs, and trade are necessary complements to most subsidy programs.

This immediately suggests that African governments cannot achieve their goals for productivity growth by simply tallying higher figures on volumes of fertilizer distributed or public funds allocated to fertilizer distribution. Rather, governments will need to take the much more challenging, long-term path of investing in crop breeding and agronomy programs, irrigation development, soil testing, and extension services to educate farmers about soil fertility management practices and the adoption of complementary inputs to increase fertilizer response rates and profitability. While there are examples of best practices for public investment in these areas-African centers of breeding excellence, high-resolution soil mapping and testing programs, large-scale extension services-much more investment is still required. For instance, public agricultural research spending as a share of agricultural gross domestic product (GDP) was only 0.39 percent in Africa south of the Sahara in 2016, far below the minimum investment target of 1 percent of agricultural GDP recommended by the African Union and the United Nations (ASTI 2020).

Another important question relates to the absence of effective fertilizer policy in many countries. While most African countries have a wide variety of fertilizer polices, only about one-third have formal fertilizer policies specifically designed to regulate the sector. Instead of standard regulations, many governments use decrees or ad hoc guidelines, which are subject to frequent changes that create uncertainties and thereby disincentivize private sector participation (AGRA 2019). Studies also show that fertilizer polices and legislation in most African countries are (1) outdated and thus insufficient or inappropriate to regulate new fertilizer products and production technologies; (2) generic and include provisions about other agricultural inputs, and as a result lack important details; and (3) characterized by inadequate enforcement (IFDC 2015). Several countries have taken significant steps to reformulate and update their fertilizer policies and regulations, including Burkina Faso, Ghana, Kenya, Mali, Mozambique, Rwanda, Tanzania, Uganda, and Zambia (AGRA 2019). But more evidence will be needed to determine whether these reformulations and updates will have the desired effects on fertilizer use by farmers and, more specifically, among those farmers who stand to gain the most and contribute most significantly to productivity growth.

While reviewing the impact of each and every national policy on fertilizer use is beyond the scope of this chapter, we attempt to assess the types and effects of the most commonly used policy instrument in Africa: fertilizer subsidies. ${ }^{1}$ Table 4.1 presents the types of subsidy policies adopted by select African countries, the cost of the input subsidy as a share of public spending on agriculture, and the growth in fertilizer consumption and application rates during the period 2006 to 2017. These figures-though dependent on highly aggregated figures from FAOSTAT and insensitive to heterogeneity across crops, farm-household types, farming systems, market conditions, and agroecological context-suggest no particularly close relationship between the type or share of expenditure on

1 See Jayne et al. (2018) and Holden (2019) for a detailed discussion on the effects of fertilizer subsidy programs on fertilizer use, productivity, and related outcomes in Africa. These studies cover recent innovations and types of subsidies (for example, e-vouchers). 
input subsidies and growth in fertilizer consumption and application rates. ${ }^{2}$ Yet the figures in Table 4.1 also suggest that fertilizer subsidies-regardless of how effective they might be-have major implications for national budgets. On average, fertilizer and input subsidies in Africa amounted to about 14-26 percent of the national budget allocated for agriculture during 2011-2014 (Jayne et al. 2018).

TABLE 4.1-INPUT SUBSIDY POLICIES AND FERTILIZER USE GROWTH RATES, SELECTED AFRICAN COUNTRIES

\begin{tabular}{|c|c|c|c|c|}
\hline $\begin{array}{l}\text { Type of input } \\
\text { subsidy }\end{array}$ & Country & $\begin{array}{l}\text { Input subsidy } \\
\text { cost as a share } \\
\text { of public } \\
\text { agricultural } \\
\text { spending } \\
(\%, 2014)\end{array}$ & $\begin{array}{c}\text { Fertilizer } \\
\text { consumption } \\
\text { growth rate }(\% \text {, } \\
\text { 2006-2017) }\end{array}$ & $\begin{array}{c}\text { Average } \\
\text { fertilizer } \\
\text { application } \\
\text { growth rate } \\
(\%, 2006-2017)\end{array}$ \\
\hline \multirow{5}{*}{ Universal subsidy } & Burkina Faso & 13.8 & 6.0 & 4.0 \\
\hline & Ghana $^{a}$ & NA & 11.0 & 10.0 \\
\hline & Mali & 9.0 & 25.0 & 24.0 \\
\hline & Nigeria & 10.8 & 17.0 & 17.0 \\
\hline & Senegal & 9.2 & 30.0 & 27.0 \\
\hline \multirow{5}{*}{ Targeted subsidy } & Côte d'Ivoire & NA & 14.0 & 12.0 \\
\hline & Kenya & 16.1 & 0.0 & -1.0 \\
\hline & Malawi & 44.5 & 1.0 & 0.0 \\
\hline & Tanzania & 12.8 & 13.0 & 10.0 \\
\hline & Zambia & 19.9 & 14.0 & 12.0 \\
\hline $\begin{array}{l}\text { Other type of } \\
\text { subsidy }^{\mathrm{b}}\end{array}$ & Ethiopia & 19.9 & 14.0 & 12.0 \\
\hline \multicolumn{5}{|c|}{$\begin{array}{l}\text { Source: FAO (2020). } \\
\text { Note: Fertilizer consumption is based on the amount used in agriculture (that is, agricultural use). The } \\
\text { types and costs of input subsidy are adapted from Jayne et al. (2018). a For Ghana, the cost of the input } \\
\text { subsidy as a percentage share of public agricultural spending was } 31.6 \text { in } 2013 \text {. b As indicated in Jayne et al. } \\
\text { (2018), the Ethiopian government does not consider public spending related to fertilizer procurement and } \\
\text { distribution as a subsidy. NA = not available. }\end{array}$} \\
\hline
\end{tabular}

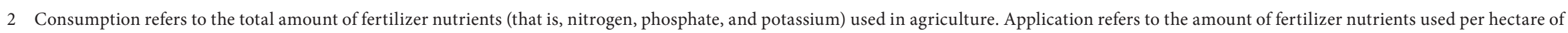

Consump
cropland.

\section{The Returns to Fertilizer Use}

Given cross-country variations in fertilizer policy and fertilizer use, it is important to think more closely about the heterogeneity in application rates and returns in any analysis of fertilizer (for example, Duflo, Kremer, and Robinson 2008, 2011; Minot and Benson 2009; Minten, Koru, and Stifel 2013; Rashid et al. 2013; Sheahan and Barrett 2017; Binswanger-Mkhize and Savastano 2017; Abay et al. 2018). Absolute consumption of fertilizer and application rates per hectare of cropland in Africa lag significantly behind other regions of the world. For instance, in 2017, the continent accounted for only 3.3 percent of global fertilizer used in agriculture (Figure 4.1 and Figure A4.1 in the appendix). This has been the case over the last two decades (Figure A4.2 in the appendix). However, aggregate fertilizer consumption has not declined in Africa. On the contrary, fertilizer use on the continent rose from 4.1 million metric tons in 2002 to 6.5 million metric tons in 2017 (Figure A4.2 in the appendix). This represents a 3.5 percent annual growth rate over that period, on average. As one would expect, disaggregated analysis at (selected) country levels indicates that fertilizer consumption varies significantly across countries. Countries with major shares of fertilizer consumption on the continent include Ethiopia, Kenya, Malawi, Mali, Nigeria, and South Africa (Figure A4.2 in the appendix).

The average fertilizer application rate per hectare of cropland has also been growing over the last two decades in Africa, but at a lower rate than that of absolute consumption (partly because cropland on the continent also increased during the same period). Fertilizer application rates increased from 17.7 kilograms of nutrients per hectare of cropland in 2002 to 23.3 kilograms of nutrients per hectare of cropland in 2017. This represents a 2 percent annual growth rate over that period, on average. Again, disaggregated analysis at the country level shows that while application rates overall are low compared to those in other parts of the world, they are not uniformly low across countries. For instance, application rates are relatively higher in Kenya, Mali, Malawi, and Zambia (Figure 4.2). Application rates are also variable across regions (production zones), crops, and households within a country (Jayne and Rashid 2013; Sheahan and Barrett 2017). The aggregate application rates shown in Figure 4.2 are roughly 
FIGURE 4.1-FERTILIZER CONSUMPTION AND APPLICATION RATE BY REGION (2017)

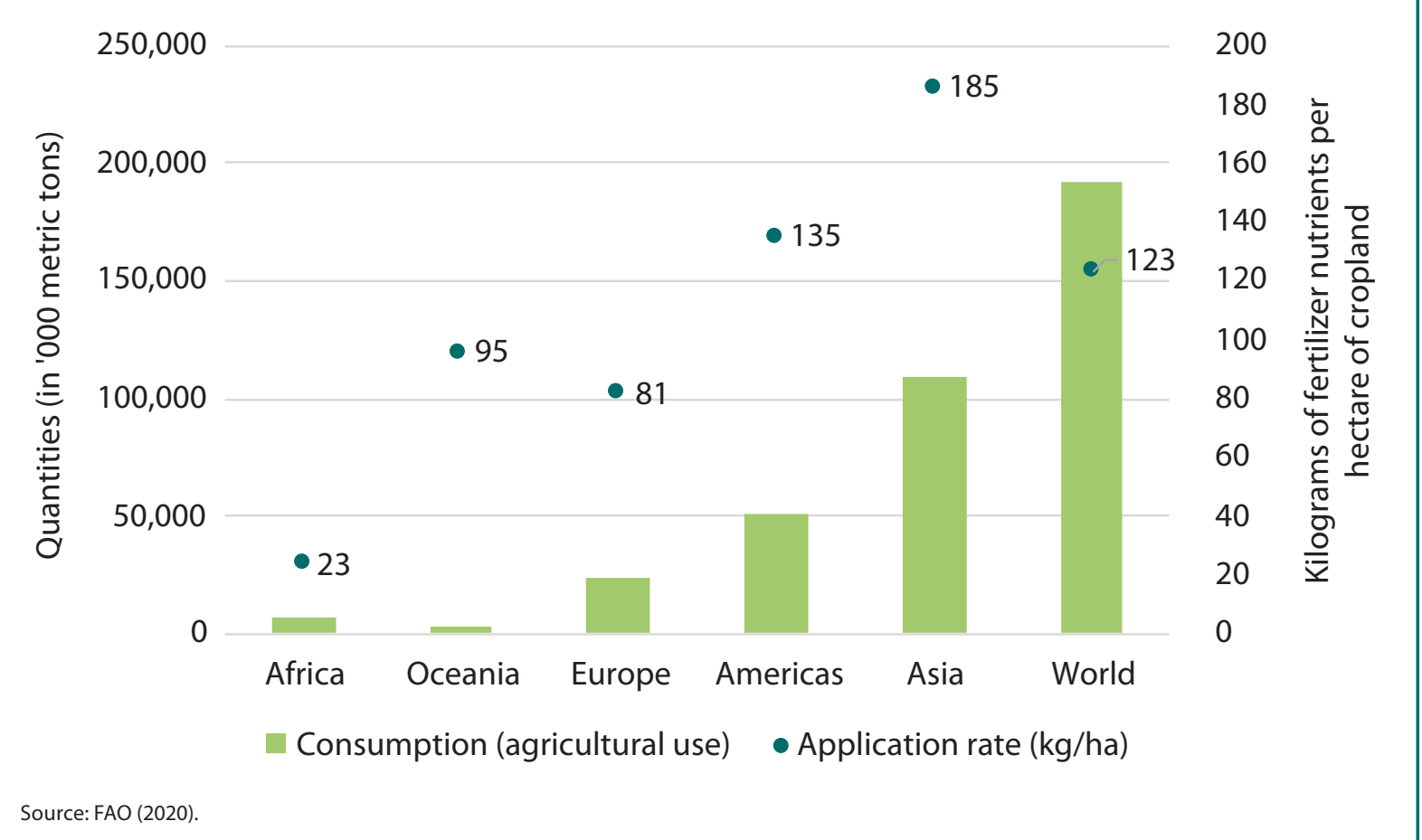

comparable to the micro-level application rates obtained from household surveys (for example, Sheahan and Barrett 2017).

Many socioeconomic and behavioral factors contribute to the low adoption and application rates of fertilizer in Africa, some of which are surmountable with the deployment of appropriate public policies and investments. The most common factors are related to market imperfections (Moser and Barret 2006; Giné and Yang 2009; Foster and Rosenzweig 2010; Duflo, Kremer, and Robinson 2011; Minten, Koru, and Stifel 2013), risks and uncertainty (Kelly and Crawford 2007), and low marginal returns to fertilizer use (Marenya and Barrett 2009; Burke et al. 2017; Liverpool-Tasie 2017; Suri 2011).

The first and best-understood constraint relates to access and supply-related factors. Access and availability of fertilizer continues to be a major factor in the low adoption and application rates of fertilizer in most African countries.
Fertilizer is either not available at all or not supplied at the right time and place and in the right formulation (see, for example Croppenstedt, Demeke, and Meschi 2003; Davis et al. 2010; Spielman,

Kelemwork, and Alemu 2012). Supply constraints are often linked with poor infrastructure and an unfavorable policy and business environment for private sector participation (Kelly and Crawford 2007; Minten, Koru, and Stifel 2013).

Liquidity and credit constraints are also widely documented in studies on fertilizer and fertilizer policy. Fertilizer application involves significant costs for the purchase of the product itself and its transportation to the farm. For most farmers this requires that they have cash on hand, assets that can be liquidated into cash, or access to credit.

However, most smallholder farmers in Africa have few, if any, of these resources: cash is often difficult to accumulate and retain, asset liquidation may be immiserating, and credit may be in short supply due to underdeveloped rural capital markets and financial services (Croppenstedt, Demeke, and Meschi 2003; Moser and Barrett 2006; Dercon and Christiaensen 2011; Karlan et al. 2014).

Even where liquidity or credit constraints are lifted, the high cost of fertilizer may make it simply unaffordable to the farmer. African farmers pay the highest price for fertilizer anywhere in the world. Last-mile fertilizer prices are higher in Africa due to high transaction (logistic and transportation) costs that mainly emanate from poor road and storage infrastructure and long distances from ports to production areas (Kelly and Crawford 2007; Minten, Koru, and Stifel 2013; AGRA 2019). Reductions in transportation costs as a result of improved road infrastructure can reduce fertilizer prices and lift the output-to-fertilizer price ratio to a level that makes higher fertilizer application profitable (Minten, Koru, and Stifel 2013; Liverpool-Tasie 2017).

Because of these costs, several studies show that higher fertilizer prices coupled with low output prices make fertilizer use unprofitable in some African 


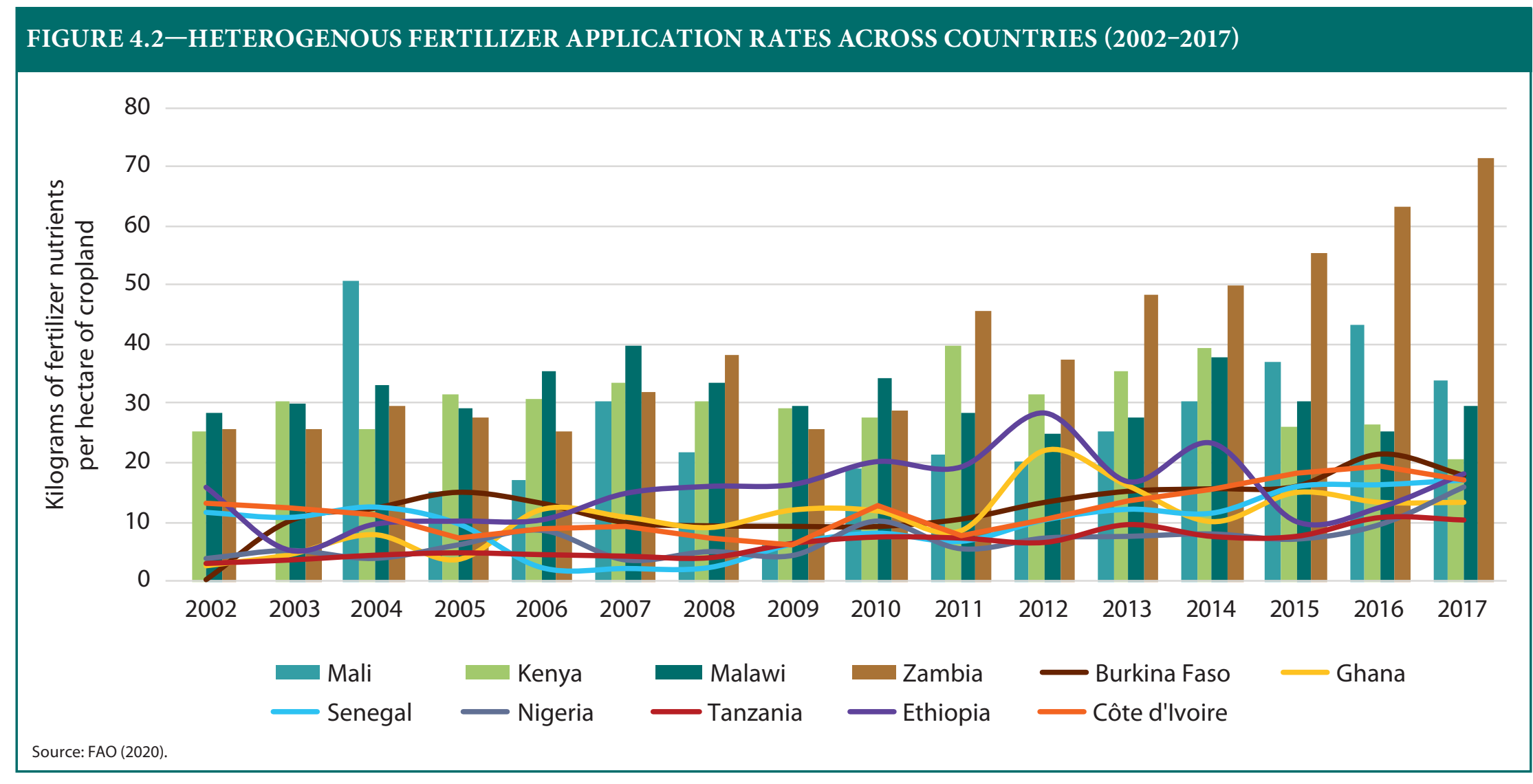

soils and contexts, particularly in remote areas and production zones with low crop response rates (Kelly and Crawford 2007; Duflo, Kremer, and Robinson 2008; Marenya and Barrett 2009; Conley and Udry 2010; Foster and Rosenzweig 2010; Suri 2011; Minten, Koru, and Stifel 2013). A common measure of fertilizer profitability is the marginal value cost ratio (MVCR), which captures a crop's response rate to fertilizer (that is, the units of output produced from a unit of nutrient) and the relationship between fertilizer and crop/commodity prices. A recent review of MVCR estimates for maize plots in Africa indicates that fertilizer use is either unprofitable or only marginally profitable in many contexts (Jayne and Rashid 2013). Similar studies on profitability of fertilizer application on maize farms arrive at similar conclusions for farms in Benin (Tovihoudji 2018), Burkina Faso (Theriault, Smale, and Haider 2018), Burundi (Niyuhire et al.
2017), Ethiopia (Rashid et al. 2013), Ghana (Ragasa and Chapoto 2017), Nigeria (Liverpool-Tasie 2017), Tanzania (Mather et al. 2016), and Zambia (Burke, Thom, and Black 2017). Factors correlated with returns to fertilizer use include agroecological context and production systems (for example, irrigated versus rainfed, high-potential versus fragile production zones) and soil characteristics (for example, soil $\mathrm{pH}$ levels).

A significant dimension of the variability in marginal returns to fertilizer use is also directly related to the risks and uncertainties associated with agricultural production. Although some countries are exploring pilots and large-scale risk transfer programs, production and price risks coupled with uncertainty about climate patterns and trends tend to compound the issue of low returns (Croppenstedt, Demeke, and Meschi 2003; Foster and Rosenzweig 2010; Giné 
and Yang 2009; Dercon and Christiaensen 2011). And when combined with the fact that many farmers have limited access to extension services and thus the agronomic knowledge and skills needed to use fertilizer efficiently, it should not be surprising that low use rates and returns are such a prominent part of the African agricultural narrative (see, for example, Kelly and Crawford 2007; Krishnan and Patnam 2014; Jayne et al. 2018).

More recently, evolving research has also turned its attention to other, more behavioral factors limiting fertilizer adoption in Africa. These factors include information asymmetries affecting farmers' perceptions that the fertilizer they purchase is low quality or counterfeited (see, for example, Bold et al. 2017; Fairbairn 2017), though this situation may not be as widespread as claimed; present-biased behavior that makes it difficult to save for bulky fertilizer purchases (Duflo, Kremer, and Robinson 2011); and other behavioral and psychological explanations such as aspiration failures (Abay, Blalock, and Berhane 2017; Taffesse and Tadesse 2017). These perspectives may not only explain low fertilizer use rates but also suggest that farmers switch back and forth between using and not using fertilizer across seasons in response to new information about marginal returns, for example, information on expected yield response, fertilizer price, and output price (Duflo, Kremer, and Robinson 2008; Conley and Udry 2010; Suri 2011).

\section{Soils, Nutrients, and Fertilizers: Returning to First Principles}

Returning to first principles, the economic and behavioral dimensions of fertilizer use and adoption may depend on how we answer basic scientific questions relating to soils and agronomy. Jayne and Rashid (2013) show a constant trend of cereal output-to-fertilizer price ratios over a 20-year period (1990-2012) in several African countries and suggest that changes in returns to fertilizer use and profitability may be driven primarily by crop-specific fertilizer response rates. Efforts to sustainably increase fertilizer response rates hinge on the type of cultivar, the production system and agroecology, soil characteristics, and management practices (Marenya and Barrett 2009; Tittonell and Giller 2013).

Several studies show that heterogeneity in the returns to fertilizer use in Africa can be explained by soil type (for example, Duflo, Kremer, and Robinson 2008; Marenya and Barrett 2009; Suri 2011; Burke, Thom, and Black 2017). For instance, some studies find that low soil fertility and soil acidity can render inorganic fertilizers unprofitable (Marenya and Barrett 2009; Burke, Thom, and Black 2017). These studies relate the heterogenous adoption of inorganic fertilizers across households and plots to soil properties. This is consistent with well-established agronomic literature showing that yield responses to fertilizers depend heavily on soil nutrient requirements and farmers' response to these nutrient requirements (for example, Tittonell et al. 2008; Kihara et al. 2016). Different types and brands of chemical fertilizers contain varying types and levels of nutrients, which implies that the profitability of these fertilizers would depend on specific soil nutrient requirements and associated applications. However, a substantial share of fertilizer applied on African soil is nitrogen (Sheahan and Barrett 2017; FAO 2020).

In most cases, objective measures of soil properties and associated agronomic requirements are not easily available to and accessible by smallholders in Africa. Traditional soil tests are usually expensive and inaccessible to smallholder farmers in most of Africa, and the tests that do exist are not at high spatial resolution (Gourlay et al. 2017). This implies that farmers lack accurate knowledge about the properties and nutrient requirements of their soil. Furthermore, these soil nutrient requirements are expected to vary significantly across communities, which limits farmers' ability to learn about their soils (Tjernstrom 2017). In the presence of significant spatial and plot-level variability in soil properties, the usually generic and "blanket" fertilizer recommendations in many African countries are less relevant to many farmers (see, for example, Jayne et al. 2002, 2003). Indeed, as farmers become aware that agronomic recommendations are not site-specific and fertilizer types available in local markets are generic, they usually pay less attention to these blanket recommendations. In the absence of objectively measured soil properties, farmers usually rely on some inaccurate proxies to learn about their soils (Berazneva et al. 2018). Input use responses and associated behavioral adjustments driven by these misperceptions are less likely to be optimal and productivity-enhancing.

To address this information asymmetry associated with soil properties, new innovations in soil testing technologies and associated site-specific fertilizer recommendations are evolving. New and low-cost soil testing kits are being employed to generate site-specific information and provide site-specific agronomic recommendations that fit local production conditions. Recent evaluations of the potential of these innovations show encouraging results (for example, Harou et al. 2018; Murphy et al. 2019; Ayalew, Chamberlin, and Newman 2020). 
These studies find that site-specific recommendations can increase farmers' investments in agricultural inputs (Harou et al. 2018; Murphy et al. 2019) and boost agricultural yields (Ayalew, Chamberlin, and Newman 2020). The studies also show that individualized soil testing technologies can help address potential information asymmetries relating to soil properties and the associated mismatch between soil nutrient requirements and fertilizer application rates. However, these studies are based on small soil testing experiments, and large-scale sitespecific testing facilities are beyond the reach of smallholders in many African countries (Gourlay et al. 2017). Establishing localized soil laboratories and soil testing facilities along with the promotion and supply of multiple products (for example, lime to treat acidic soils, fertilizer blends that are specific to crop and soil type) should be among the main fertilizer policy priorities on the continent. This obviously requires major investments, and some African countries (for example, Ethiopia) are now investing in research and development in these types of facilities. Reviving and revitalizing localized agricultural extension systems may help smallholders obtain customized recommendations and hence maximize local production potential.

This then opens the door to questions about the sustainable use of fertilizer, or the role of precision nutrient management in African agriculture.

Agronomically appropriate and sustainable application of chemical fertilizers is crucial for maximizing the marginal returns from fertilizer applications and for ensuring environmental health. Overuse and underuse of chemical fertilizers is both inefficient from an economic perspective and harmful to soil, water, and environmental health. Population pressure and soil degradation are leading to significant nutrient depletion in many African countries, implying increasing soil nutrient requirements and hence a growing need for appropriate chemical fertilizer applications (see, for example, Kassie et al. 2008). This situation is further aggravated by increasing soil acidity (Tittonell and Giller 2013), which together with the low application of chemical fertilizers threatens sustainable food security in Africa. Deviations from agronomic recommendations may indicate that farmers are not exploiting the maximum potential of chemical fertilizers or that they are incurring additional fertilizer costs with little yield gain (see, for example, Yadav et al. 1997).

While the overall application of fertilizers in many parts of Africa remains low, there exist significant heterogeneities across countries, including significant overapplication in some African countries (Kurdi et al. 2020). Focusing on Egypt,
Kurdi et al. (2020) document that average nitrogen fertilizer application rates are substantially higher than (crop-specific) agronomic recommendations. This study further highlights that the fertilizer subsidy program in Egypt contributes to this overapplication of chemical fertilizers, suggesting that generous subsidy programs in Africa may encourage farmers to deviate from agronomically recommended fertilizer usage practices, with some important implications for households, the overall economy, and the environment.

While the impact of potential overuse of chemical fertilizers in Africa has yet to be researched, several studies document significant adverse environmental impacts of chemical fertilizer application in European countries (Sutton et al. 2011) and Asian countries (Zhang et al. 2013). Because of the increasing use and production of chemical fertilizers, mainly nitrogen fertilizers, curbing nitrogenrelated emissions and the associated environmental impacts will likely be a major challenge of the 21st century (Sutton et al. 2011; Zhang et al. 2013). The annual environmental damage cost associated with nitrogen fertilizer application in the European Union is estimated to be between $€ 70$ billion and $€ 320$ billion, while the corresponding environmental cost associated with nitrogen fertilizer production and damage in China is expected to be even higher (Zhang et al. 2013). Excessive environmental damage can affect the overall yield gains and marginal returns associated with chemical fertilizers, sometimes to the level that the adverse health and environmental impacts outweigh the economic gains from fertilizer application (van Grinsven et al. 2013).

These pieces of evidence suggest that even though the overall fertilizer application rates in many African countries remain low, agronomically appropriate and sustainable application of chemical fertilizers is crucial to maximize the yield-enhancing impact of chemical fertilizers. Agronomic and sustainability recommendations should be informed by important investments in research and development, a sector lacking significant spending among many African countries. Strengthening and expanding existing extension systems in Africa can help ensure appropriate adoption of modern agricultural inputs and improve agricultural productivity (see, for example, Berhane et al. 2018; Ragasa and Mazunda 2018). These investments in research and development are likely to generate locally appropriate soil information and agronomic recommendations that can minimize potential inefficiencies and damage due to information asymmetries associated with soil properties or recommendations. 


\section{The Political Economy of Fertilizer Policy}

We know a great deal about the relationships between fertilizer use, public policy, and agricultural productivity growth in Africa. Sheahan and Barrett (2017) argue that differences in the policy and operating environments of countries matter in terms of explaining the observed variation in use of inorganic fertilizer in selected African countries - that is, a combination of policy, institutional, and macroeconomic variables explain a substantial share of the micro-scale variation in fertilizer use more than household-level and agroecological variables. Still, it is somewhat surprising that fertilizer policy remains so prominent in the political, academic, and ideological discourse throughout the continent. Several elements in this discourse are worth noting.

First is the overarching discussion about where to invest in promoting fertilizer use in Africa. Building on Asia's experience during the Green Revolution, there is considerable economic logic in concentrating public spending on fertilizer distribution (specifically subsidies) on high-potential areas where the returns to fertilizer use are likely to be highest. These tend to be areas characterized by favorable agroecological conditions, relatively developed transportation networks, high irrigation potential, and functional market infrastructure, and these areas may depend on agrarian labor that migrates from low-potential areas of the country (Kelly and Crawford 2007; Jayne and Rashid 2013; Rashid et al. 2013). But from the perspective of social equity, many perceive this strategy as biasing public spending toward areas and households that are already better off than more marginal areas and more vulnerable populations in a country.

Second is how the debates are framed. There are strong proponents and critics of fertilizer policy and fertilizer subsidies in Africa, and considerable debate around what constitutes stories of "success" or "failure" in this space (see, for example, Morris et al. 2007; Dugger 2007; Denning et al. 2009; Sachs 2012; Jayne and Rashid 2013; Lunduka, Ricker-Gilbert, and Fisher 2013). For example, advocates of fertilizer subsidies argue that insurmountable market and institutional failures-geographic fragmentation of markets, high transaction costs, inefficient markets for financial services, and information asymmetriesnecessitate state intervention in the form of subsidies. Their premise rests on the expectation that once use of subsidized fertilizer becomes widespread, farmers will recognize its profitability and the subsidy can be withdrawn slowly over time without compromising household incomes or national food security. At the opposite end of the spectrum is the neoclassical economists' argument that market-driven pricing of fertilizer without state intervention is ultimately the most efficient way to allocate the scarce resources held by both households and governments and will ultimately lead to profitable rates of fertilizer application.

Malawi's experience with fertilizer policy reforms remains one of the most commonly cited experiments with subsidies, although few truly agree on the design of the policy, the details of how it was actually implemented, or its outcomes (see, for example, Denning et al. 2009; Dorward and Chirwa 2011; Sachs 2012; Jayne and Rashid 2013; Jayne et al. 2018). This experience has inspired impact evaluations of fertilizer subsidies in other African countries, some of which find positive results, while others find far more ambiguous outcomes (see, for example, Chibwana et al. 2014; Jayne et al. 2013; Lunduka, Ricker-Gilbert, and Fisher 2013; Mason and Jayne 2013; Wossen et al. 2017).

In Africa, the reality likely lies somewhere between these ardently held positions in the current discourse. Studies show that in some instances, farmers already apply an optimal level of fertilizer given their constraints, comparative advantages, and expected profits (for example, Conley and Udry 2010; Suri 2011; Liverpool-Tasie 2017). Other studies show that fertilizer subsidies crowd out commercial fertilizer purchases, hamper private sector development, and lead to environmentally damaging overuse and abandonment of other soil fertility management practices (Mason and Jayne 2013; Ricker-Gilbert, Jayne, and Chirwa 2011; Takeshima and Nkonya 2014; Ricker-Gilbert and Jayne 2017; Morgen et al. 2019; Kurdi et al. 2020).

Other studies show that even the best-designed fertilizer policies and subsidy programs are extremely difficult to operationalize and can have severe unintended consequences. These challenges relate primarily to inefficient targeting of subsidies and the rent-seeking opportunities created by such targeting. Jayne et al. (2013) find that about 33 percent of subsidized fertilizer does not reach the actual intended beneficiaries in some African countries because of leakages and diversions of fertilizer. Similarly, several other studies show that a substantial share of fertilizer and other input subsidies does not reach poor, vulnerable, or marginalized farmers because of targeting problems (Lunduka, Ricker-Gilbert, and Fisher 2013; Chibwana et al. 2014; Holden and Lunduka 2012; Ricker-Gilbert, Jayne, and Chirwa 2011). Elite capture in these programs is also well documented (Ricker-Gilbert, Jayne, and Chirwa 2011; Pan and Christiaensen 2012).

Thus, there have been efforts to recast these programs as "smart" subsidies that are astutely managed, carefully targeted, and technologically advanced. For instance, Nigeria recently introduced an innovative mobile phone-based input 
subsidy program that delivers fertilizer subsidies through electronic vouchers (see, for example, Wossen et al. 2017). Many other countries (for example, Malawi, Mozambique, Rwanda, Zambia, and Zimbabwe) are following this lead and introducing some form of these smart and innovative subsidies (for example, e-wallet, e-voucher). The effectiveness and potential impacts of these recent innovations and smart subsidy programs, some of which are yet to be studied, are likely to depend on the institutional and political contexts in which they are introduced (Jayne et al. 2018).

This opens the door to the political economy dimensions of fertilizer policy and subsidy programs. In Africa, there is a widely held belief that these policies and programs are popular among voters and help politicians secure, consolidate, or retain power. Yet the empirical evidence on such a relationship is mixed at best (Banful 2011; Jayne and Rashid 2013; Ricker-Gilbert et al. 2013; Mason, Jayne, and Van De Walle 2017; Jayne et al. 2018). Unfortunately, such evidence has had very limited influence on the debates about fertilizer policy in Africa.

\section{Conclusions and Recommendations}

There is a common understanding that an "African Green Revolution" requires increased use of improved agricultural inputs such as fertilizer and improved seeds. Adoption of these inputs is particularly crucial for those countries where agriculture remains the major source of livelihoods for poor households and low agricultural yields persist. In these contexts, boosting agricultural productivity remains the most effective strategy to reduce poverty and ensure food security. This has been recognized, as manifested by, for example, the Abuja and Malabo Declarations and calls for improving access to quality and affordable agricultural inputs through the provision of targeted supports.

A wide range of fertilizer and other input promotion polices in most African countries are geared toward improving affordable access to improved agricultural inputs. For instance, national fertilizer policies and regulations mainly focus on the formulation of instruments that can reduce farmgate fertilizer prices and increase fertilizer application rates. However, the evidence base on the efficacy and impact of these policies (for example, subsidies) remains mixed, with success stories for some modalities and countries. The mixed evidence base warrants further refinements and improvements in the modalities and targeting of these policies as well as the institutional contexts in which these policies operate. Continentwide programs such as CAADP and initiatives by regional economic communities can play a vital role in facilitating the refinement and harmonization of fertilizer policies across borders. Regional communities can also play an indispensable role in promoting inter- and intraregional fertilizer trade, which is long overdue, as are closer scrutiny of and remedial measures to reduce the negative environmental externalities of intensive fertilizer use.

Despite significant increases in aggregate fertilizer consumption and application rates over the last two decades (due in part to the above-mentioned policies), fertilizer use and application rates remain remarkably low in Africa as compared to other parts of the world, though there is significant variation across countries, agroecological zones, production systems, and households. Lower and variable application rates are often linked with lower and variable returns to fertilizer uses, that is, fertilizer application can be unprofitable (or only marginally profitable) in contexts where output-to-fertilizer price ratios are lower and in production zones with low crop response rates (for example, production zones with acidic or less fertile soils). Poor infrastructure in some African countries and associated high transport and transaction costs further reduce these price ratios and profit margins. This suggests that investment in rural infrastructure could help make fertilizers and other improved inputs more profitable and appealing to farmers.

Generic and "blanket" fertilizer recommendations in the presence of substantial spatial variability in soil properties, which is common in most African countries, are also likely contributing to the low returns and application rates. Cognizant of the generic nature of most recommendations and the spatial variations in nutrient requirements, a few African countries are starting to invest in soil testing infrastructure to generate site-specific information and recommendations that fit local production conditions. While the results from tailored fertilizer recommendations are encouraging, coverage remains extremely limited, and this necessitates investment in large-scale soil testing facilities. Site-specific recommendations are crucial for increasing crop response rates and maximizing marginal returns. Site-specific recommendations are also important to ensure the sustainable intensification of African agriculture, including in contexts where subsidy programs have resulted in overuse of fertilizers. Underuse and overuse of fertilizers is both inefficient from an economic perspective and harmful to soil, water, and environmental health. Revitalizing existing (and mostly poorly funded) extension systems can also enable farmers to access integrated soil fertility management practices, including site-specific recommendations, and facilitate the sustainable intensification of African agriculture. 
FIGURE 4A.1-FERTILIZER APPLICATION RATES BY REGION (KG OF NUTRIENTS PER HA OF CROPLAND, 2002-2017)

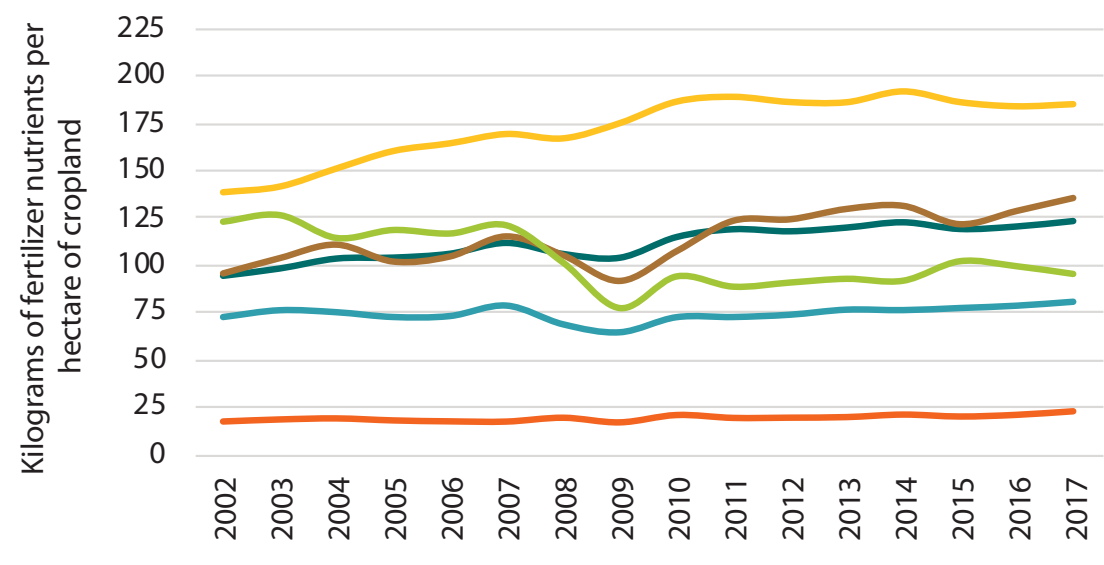

World —Africa —Americas $\longrightarrow$ Asia Europe Oceania

Source: FAO (2020)

FIGURE 4A.2-FERTILIZER CONSUMPTION IN SELECTED AFRICAN COUNTRIES (TOTAL NUTRIENTS USED IN AGRICULTURE, 2002-2017)

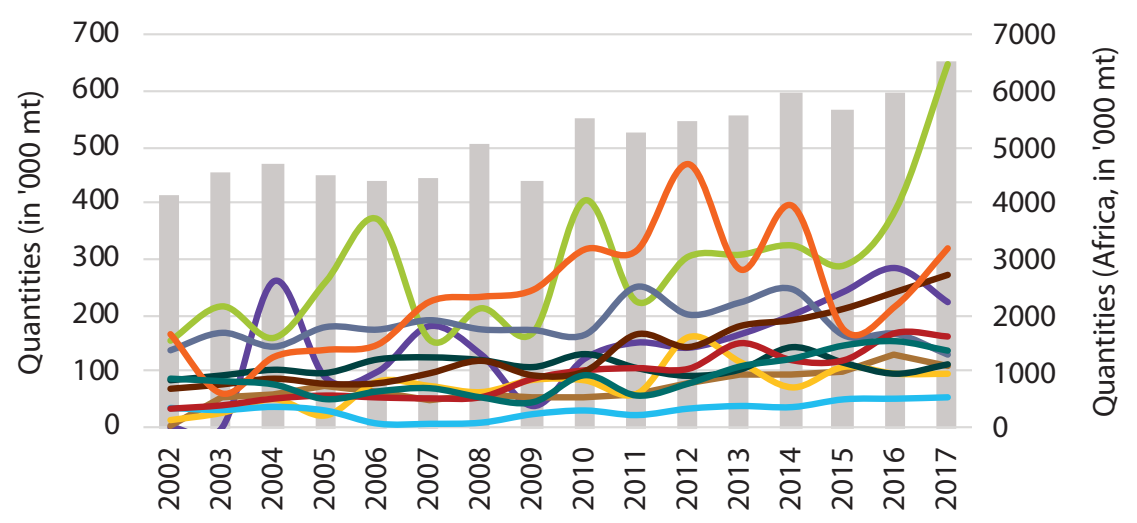

$$
\begin{array}{clll}
\text { Africa } & \text { Mali } & \text { Burkina Faso } & \text { Ghana } \\
\text { Senegal } & \text { Nigeria } & \text { Kenya } & \text { Malawi } \\
\text { Tanzania } & \text { Zambia } & \text { Ethiopia } & \text { Côte d'Ivoire }
\end{array}
$$

Source: FAO (2020) 